\title{
Septal Fetal Tissue Transplants Restore Long-Term Potentiation in the Dentate Gyrus of Fimbria-Formix-Lesioned Rats
}

\author{
Jorge A. Bergado, Heriberto Moreno, Johanka Soto, Orlando Castellano and Lázara Castillo \\ International Center for Neurological Restoration, Havana City, Cuba
}

\section{SUMMARY}

Two groups of Sprague-Dawley male rats received bilateral aspirative lesions of the fimbria fornix under chloral hydrate anesthesia. One group $(n=9)$ received no further treatment (lesioned). In the second group $(n=8)$, a piece of septal fetal tissue, obtained at day E15-16, was implanted into each lesion cavity (transplanted). A third group consisted of shamlesioned rats (controls, $n=14$ ). Two months after the operations, a recording electrode was implanted in the hilar region of the dentate gyrus of each animal, and a bipolar stimulating electrode was implanted in the perforant path. Long-term potentiation at $400 \mathrm{~Hz}$ was induced and followed for two hours. FF-lesioned rats showed an impaired potentiation of the field excitatory post-synaptic potential, which rapidly declined to basal levels within 15 minutes. The transplanted rats showed a normal potentiation of this parameter, similar to that seen in the control animals. A decrease in choline acetyltransferase activity in the hippocampi of the lesioned animals showed a tendency toward recovery after septal fetal tissue transplantation. In all the dorsal hippocampal areas of the lesioned animals, acetylcholinesterase histochemistry showed an almost complete loss of enzymatic activity, which was partially restored

\footnotetext{
Reprint address:

Dr. Jorge A. Bergado

International Center for Neurological Restoration,

Avenue $25 \# 15805$, Playa 12100

Havana City, CUBA

Fax: +53-7-332420
}

by the transplants. The improved synaptic plasticity in the transplanted animals might be related to septal transplant-induced recovery of mnemonic functions.

\section{KEY WORDS}

Septal transplants, cholinergic system, choline acetyltransferase, acetylcholinesterase, hippocampus

\section{INTRODUCTION}

In rats a lesion of the fimbria fornix (FF) provokes an almost complete denervation of subcortical afferents to the hippocampus, including the cholinergic fibers of septal origin, accompanied by a severe impairment of spatial memory in the lesioned animals $/ 2 /$. Transplanting fetal septal tissue into FF-lesioned animals induces a recovery of the diminished mnemonic functions /7,13/.

Long-term potentiation (LTP) is an endurable form of synaptic plasticity, first demonstrated in the dentate gyrus of rabbits $/ 8 /$, that has been proposed as a model of the mechanism underlying functional plasticity and memory formation in the mammalian central nervous system $/ 18,24 /$. Alterations of LTP reportedly occur in FF-lesioned rats /9,33/. Previous research in our laboratory $/ 5 /$ has shown that in the rat dentate gyrus, an FF-lesion impairs LTP of the field-excitatory post-synaptic potential (f-EPSP). If a functional link exists between LTP and memory formation, then the cognitive impairment shown by FF-lesioned animals can be attributed, at least in part, to a dysfunction of the mechanisms of synaptic plasticity, which is caused by the subcortical denervation. In line with this reasoning, improved synaptic plasticity could support the recovery of the cognitive capacities seen in FF-lesioned animals 
after transplanting septal tissue $/ 7,13 /$.

The aim of the present work was to explore whether transplanting septal fetal tissue to FFlesioned rats could contribute to restoring the impaired synaptic plasticity of such animals.

\section{MATERIALS AND METHODS}

Male Sprague-Dawley (CENPALAB, Havana, Cuba) rats weighing $220-250 \mathrm{~g}$ at the time of surgery were used in this study. The animals were kept in translucent plastic cages under controlled conditions of temperature and humidity and with free access to food and water for the duration of the experiments.

Surgery was carried out under chloral hydrate narcosis $(420 \mathrm{mg} / \mathrm{kg}$ body weight, administered intraperitoneally). According to the surgical procedure, three groups were defined. The first group comprised 9 rats (FF-lesioned); two windows were opened in the skull, immediately behind the bregma and extending $1.3 \mathrm{~mm}$ posteriorly and $2 \mathrm{~mm}$ to both sides. A narrow $(\sim 0.5 \mathrm{~mm})$ bone bridge was left intact in the midline to protect the venous sinus. Through such openings, a bilateral and complete aspiration of both fornices, including the overlaying cortex and corpus callosum, was performed using a vacuum pump connected to a pipette. The lesion cavity was filled with a piece of saline-soaked gelfoam, and the skin was sutured. The lesioning of the second group of 8 rats (transplanted) was identical to that of the first group, but one piece of septal fetal tissue was implanted into each lesion cavity. The third group of rats (controls) comprised 14 animals; the skull was opened in the same way, but no aspiration was performed.

The implanted pieces of septal tissue were obtained from Sprague-Dawley rat embryos at 1516 days of gestation (E 15-16). From each embryo, the septal area was dissected from the anterior ventral region of the brain and placed into cold, buffered saline solution, which was supplemented with $0.6 \%$ glucose. The left and the right septa were separated by a knife and cut in the midline; each piece (two pieces per animal) was used for the transplant. We preferred this transplantation procedure over intrahippocampal injection of a cell suspension because we wanted to avoid damaging the cellular integrity of the hippocampal layers. Furthermore, one report $/ 10 /$ has shown that injecting fluids into the dentate gyrus causes the death of the granule cells, the main neurons of the structure.

Two months after the surgery, we carried out an electrophysiologic evaluation. The animals were anesthetized as before and mounted in a stereotactic frame (David Kopf Instruments, USA). A monopolar stainless-steel recording electrode RNE 300 (Rhodes Medical Instruments, USA) was lowered to the hilar region of the right dentate gyrus (AP: $-3.8 \mathrm{~mm}$; ML: $1.8 \mathrm{~mm}$; DV: $3.5 \mathrm{~mm}$ ), and a bipolar stimulating electrode NE 200 (Rhodes Medical Instruments, USA) to the perforant path (AP: $-7.5 \mathrm{~mm}$; ML: $4.0 \mathrm{~mm}$; DV: $4.0 \mathrm{~mm}$ from the bregma). To obtain the best morphology and sensitivity, the vertical position of the electrodes was adjusted under direct inspection of the evoked potentials. The potentials were recorded using a Neuropack 2 (Nihon-Kohden, Japan) recording system filtering between $1 \mathrm{~Hz}-10 \mathrm{KHz}$. The stimulation was performed by an SEN 3301 (NihonKohden, Japan) electronic stimulator that was connected through an SS-104J isolator to the animal, delivering square pulses $(0.1 \mathrm{mseg})$ of constant current. To determine the stimulus intensities to be applied to each animal, we constructed a stimulus-response curve, using the amplitude of the population spike (PS) as a measure of response. For the test stimuli, we used an intensity that could evoke a PS $50 \%$ of the maximal amplitude. For the induction of LTP, we used an intensity that could produce a PS of $25 \%$ of the maximal amplitude.

Test recordings were made three times before inducing LTP (basal recordings), and at 2, 5, 15, 30,60 , and 120 minutes after the tetanization. Each record consisted of the average of three successive potentials at $0.2 \mathrm{~Hz}$. LTP was induced by 10 tetanic trains of 10 pulses $(0.1 \mathrm{mseg})$ each at $400 \mathrm{~Hz}$, applied at 10-second intervals. The amplitude of the PS was measured from the start to the peak of the spike-like deflection. The slope of the f-EPSP was calculated as $\Delta \mathrm{V} / \Delta \mathrm{t}$ on the first upward deflection (SF) in each record before (basal value) and after the induction of LTP. The value of each parameter after the tetanization was expressed as percent of the corresponding pretetanization basal value. The 
level of anesthesia was maintained by injecting onethird of the initial dose two hours after the first injection and then once every hour thereafter. The body temperature was monitored and kept between $36-37^{\circ} \mathrm{C}$ with a radiant lamp. For the duration of the recording session, the hippocampal EEG was continuously monitored.

At the end of the recording session, five randomly selected animals from each group were used for determining the choline acetyltransferase (ChAT) activity in the hippocampus. Anesthetized animals were decapitated and the brains were extracted; both hippocampi were dissected in cold saline and then rapidly frozen in dry ice and stored at $-70^{\circ} \mathrm{C}$ until processed for ChAT activity according to the method described by Fonnum /12/. The remaining rats in each group were transcardially perfused with $4 \%$ paraformaldehyde$15 \%$ picric acid in $0.1 \mathrm{M}$ phosphate buffer ( $\mathrm{pH} 7.4$ ), and the brains were extracted and postfixed for $1 \mathrm{hr}$ in the same solution. The fixed brains were successively infiltrated in $7 \%, 15 \%$ and $30 \%$ sucrose solutions for $12 \mathrm{hr}$ each at $4^{\circ} \mathrm{C}$ and then frozen in isopentane chilled on dry ice. Twenty- $\mu \mathrm{m}$ coronal sections were cut with a cryostat. Sections corresponding to the lesioned area were stained with cresyl violet to assess the location and extension of the lesion and the presence of the transplanted tissue. To confirm the intensity of the cholinergic innervation, sections at the level of the dorsal hippocampus were processed for acetylcholinesterase (AChE) activity, according to the method of Karnovsky and Roots /16/. Electrophysiologic and ChAT activity data were compared among the groups using the KruskallWallis nonparametric analysis of variance, followed by a Mann-Whitney $U$ test to confirm differences between pairs of groups. In every comparison, differences with a probability of chance occurrence inferior to $5 \%(p<0.05)$ were considered significant.

\section{RESULTS}

The comparison of the initial basal values for the PS and the SF showed no differences among the groups. It should be mentioned that in some lesioned animals, we observed evoked potentials with two PS. In such cases, only the first potential was considered for the analysis. Such double-spiked potentials have been considered indicative of epileptogenic activity. Despite this finding, we found no other sign of ictal activity in the EEG, neither before, during or after tetanic stimulation. In all control animals, a clear potentiation of the PS was evident after the first record, which was taken 2 min after the tetanic stimulation (Figs. 1-2). The potentiation was maintained until the end of the observation period (Table 1).

\section{TABLE 1}

Values of mean $( \pm S E M)$ percentile change of the population spike (PS) and the slope of the f-EPSP (SF) at different times after tetanic stimulation to induce LTP

\begin{tabular}{|c|c|c|c|c|c|c|c|c|c|c|c|c|}
\hline \multirow[t]{2}{*}{ Animals } & \multicolumn{6}{|c|}{ PS } & \multicolumn{6}{|c|}{ SF } \\
\hline & $2^{\prime}$ & $5^{\prime}$ & $15^{\prime}$ & $30^{\prime}$ & $60^{\prime}$ & $120^{\prime}$ & $2^{\prime}$ & $5^{\prime}$ & $15^{\prime}$ & $30^{\prime}$ & $60^{\prime}$ & $120^{\prime}$ \\
\hline Controls & $\begin{array}{l}327.9 \\
\pm 40.8\end{array}$ & $\begin{array}{l}286.7 \\
\pm 36.4\end{array}$ & $\begin{array}{l}307.6 \\
\pm 34.9\end{array}$ & $\begin{array}{l}291.1 \\
\pm 27.6\end{array}$ & $\begin{array}{l}324.2 \\
\pm 34.3\end{array}$ & $\begin{array}{l}387.5 \\
\pm 40.6\end{array}$ & $\begin{array}{l}133.8 \\
\pm 4.9\end{array}$ & $\begin{array}{l}119.7 \\
\pm 3.7\end{array}$ & $\begin{array}{l}124.5 \\
\pm 5.6\end{array}$ & $\begin{array}{l}131.0 \\
\pm 10.6\end{array}$ & $\begin{array}{l}143.6 \\
\pm 12.1\end{array}$ & $\begin{array}{l}153.5 \\
\pm 10.9\end{array}$ \\
\hline FF-lesioned & $\begin{array}{l}346.7 \\
\pm 63.1\end{array}$ & $\begin{array}{l}339.1 \\
\pm 64.4\end{array}$ & $\begin{array}{l}310.5 \\
\pm 60.6\end{array}$ & $\begin{array}{l}330.6 \\
\pm 67.8\end{array}$ & $\begin{array}{l}335.6 \\
\pm 64.8\end{array}$ & $\begin{array}{l}344.5 \\
\pm 62.7\end{array}$ & $\begin{array}{l}132.6 \\
\pm 14.7\end{array}$ & $\begin{array}{l}117.6 \\
\pm 12.1\end{array}$ & $\begin{array}{l}104 *_{ \pm} \\
12.3\end{array}$ & $\begin{array}{l}102.3 \\
\pm 11.9\end{array}$ & $\begin{array}{l}102 * \pm \\
11.8\end{array}$ & $\begin{array}{l}96.4^{*} \\
\pm 12.4\end{array}$ \\
\hline Transplanted & $\begin{array}{l}365.1 \\
\pm 59.9\end{array}$ & $\begin{array}{l}344.1 \\
\pm 53.9\end{array}$ & $\begin{array}{l}313.8 \\
\pm 53.9\end{array}$ & $\begin{array}{l}264.8 \\
\pm 48.0\end{array}$ & $\begin{array}{l}309.0 \\
\pm 48.5\end{array}$ & $\begin{array}{l}334.2 \\
\pm 66.0\end{array}$ & $\begin{array}{l}138.1 \\
\pm 8.8\end{array}$ & $\begin{array}{l}131.6 \\
\pm 9.9\end{array}$ & $\begin{array}{l}128.4 \\
\pm 8.6\end{array}$ & $\begin{array}{l}128.3 \\
\pm 8.4\end{array}$ & $\begin{array}{l}130.7 \\
\pm 8.3\end{array}$ & $\begin{array}{l}132.9 \\
\pm 8.4\end{array}$ \\
\hline
\end{tabular}

*Significant differences ( $p<0.05$, Mann-Whitney/U-test) 


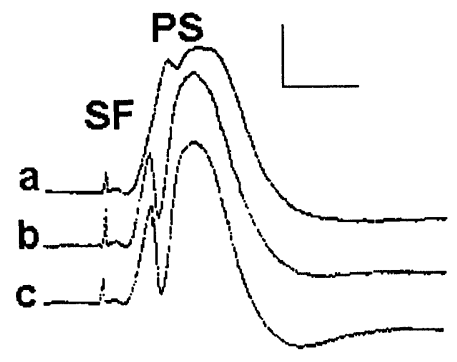

Fig. 1. Average evoked potentials in the dentate gyrus after stimulation with single pulses of the perforant path in a control rat. (a) Basal recording before the tetanization. The first, upward deflection is the f-EPSP component of the potential from which the slope (SF) was calculated. The spike-like deflection represents the population spike (PS). (b) A recording from the same animal $2 \mathrm{~min}$ after the tetanic stimulation that was used to induce LTP. (c) $120 \mathrm{~min}$ after tetanization. Scale bars $5 \mathrm{mV} / 3 \mathrm{~ms}$.

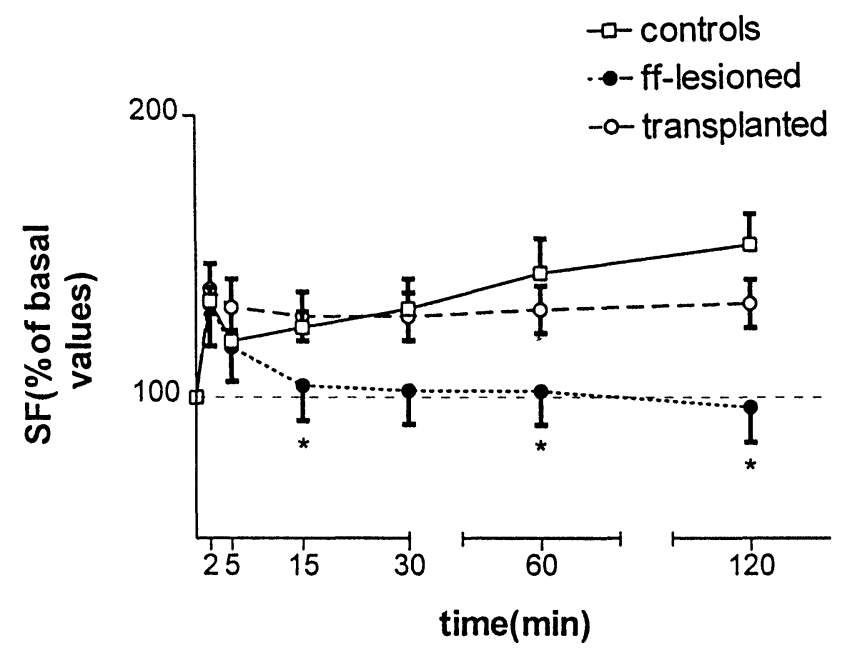

Fig. 3. Relative change of the f-EPSP (SF) slope after LTP induction. Mean values ( $\pm S E M$ ) of the percentile post-tetanization values are shown for each group. Basal pretetanization value $=100 \%$. Differences between the controls and the lesioned and between the transplanted and the lesioned $(*)$ were significant $(\mathrm{p}<0.05$, Mann-Whitney/U-test).

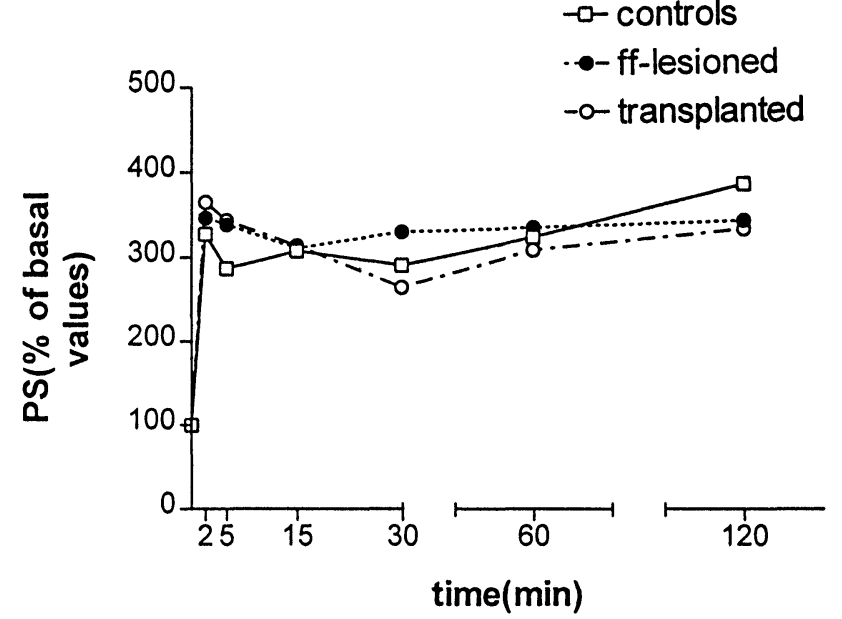

Fig. 2. Relative change of the PS after LTP induction. Mean values of the percentile post-tetanization values are shown for each group at the time points indicated. Basal pretetanization value $=100 \%$. Error bars have been omitted for clarity. The statistical comparison indicated no significant differences among the groups (Kruskal-Wallis ANOVA, $\mathrm{p}<0.05$ ).

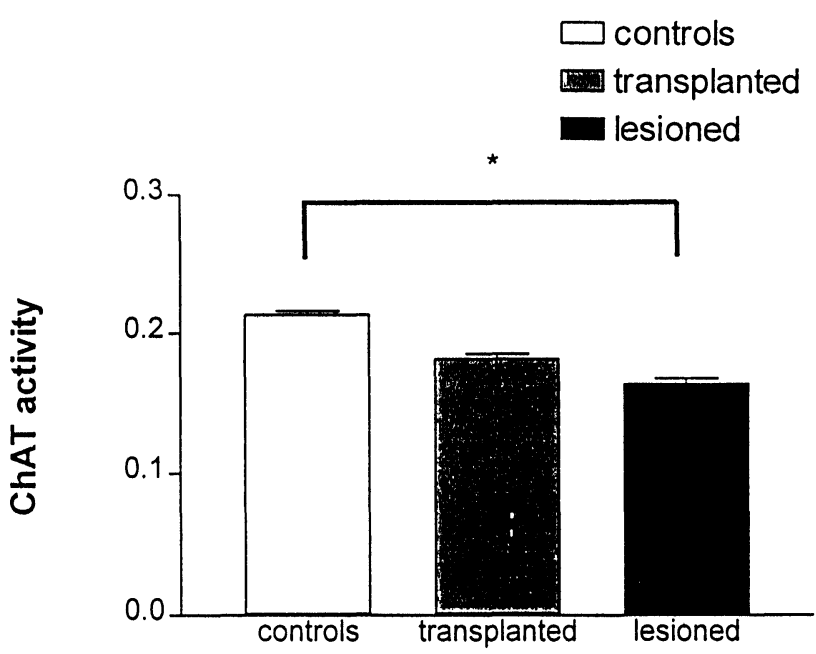

Fig. 4. Choline acetyltransferase (ChAT) activity (nmol/ $\mathrm{h} / \mu \mathrm{g}$ ) in the hippocampus of five rats randomly selected from each experimental group.

$*=p<0.05$ (Mann-Whitney/U-test) 

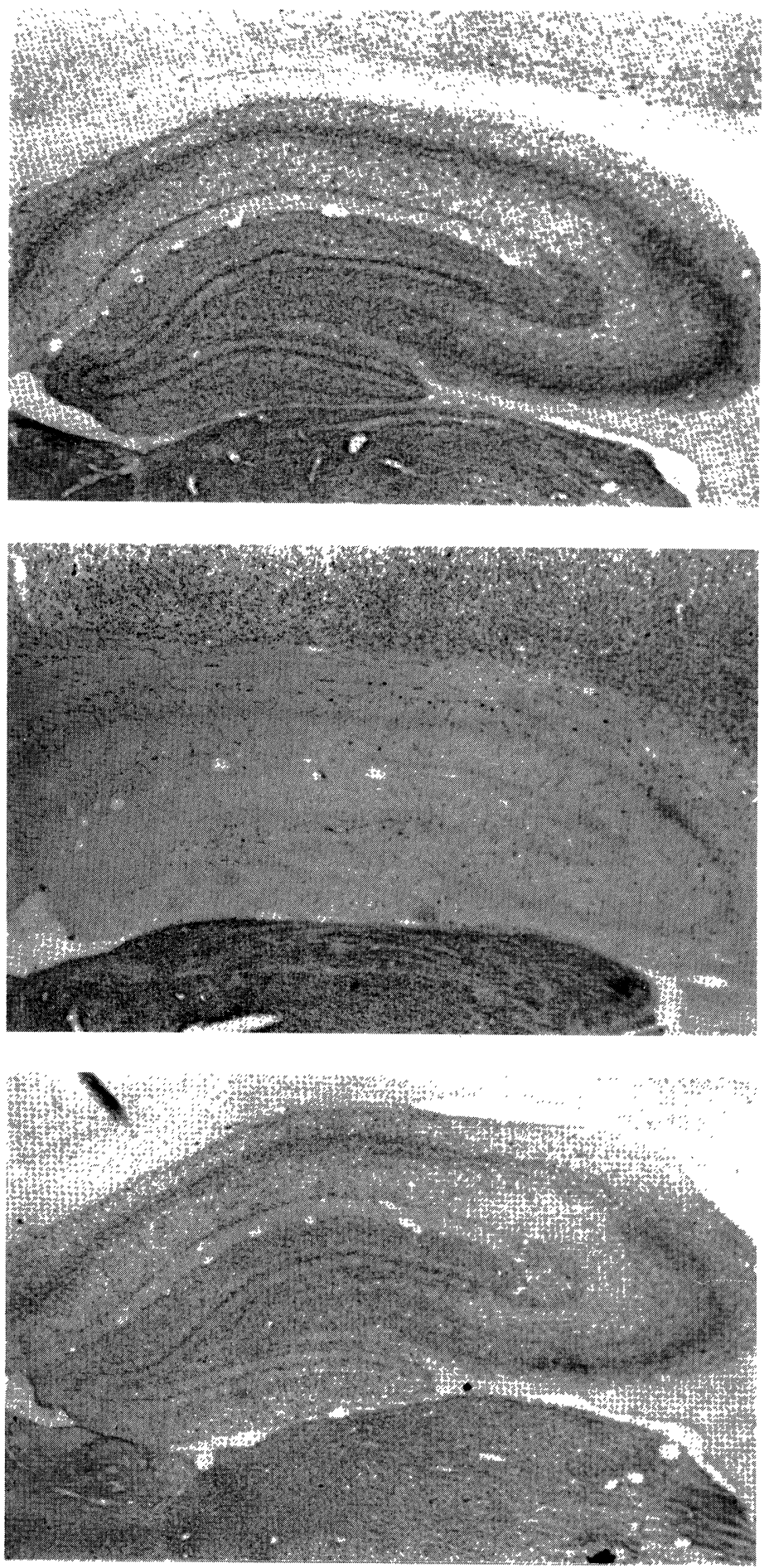

Fig. 5. Acetylcholine esterase (AChE) histochemical staining in the dorsal hippocampus of (a) control rat, (b) FF-lesioned rats, and (c) a transplanted rat. Note the intense reduction in staining after FF lesion and its partial recovery after transplantation. 
In both the lesioned and the transplanted animals, the potentiation of the PS was similar to that of the controls. The statistical analysis confirmed that no difference existed among the three groups in PS potentiation. The potentiation of the SF (Fig 3), however, showed clear differences between the control and the lesioned animals. In the control group, a potentiation of the SF was evident in all records after LTP induction, although it showed a transient decline $5 \mathrm{~min}$ after tetanization. The lesioned animals also developed an initial SF potentiation, but within $15 \mathrm{~min}$ it declined to the initial pretetanization values, with no further increase. Apparently the lesioned animals could not maintain and SF potentiation. The transplanted rats, on the other hand, behaved much like the controls, showing a sustained SF potentiation. The statistical analysis confirmed this observation; the KruskalWallis test demonstrated significant differences among the groups at 15,60 and 120 minutes after tetanization. The U-test confirmed significant differences between the controls and the lesioned and between the transplanted and the lesion animals at the same time points. No significant difference between the control and the transplanted rats appeared at any time.

The determination of ChAT activity showed a significant reduction in enzymatic activity in the hippocampus of the lesioned animals when compared with the control rats (Fig. 4). A slight recovery seems to have occurred in the transplanted rats because the values were intermediate between those of the controls and the lesioned animals and did not significantly differ from either group.

Histological analysis confirmed the total and bilateral destruction of the fimbria fornix in the lesioned and transplanted animals, extending in some rats rostrally to the septum and caudally to the tip of the hippocampus. Because of the small size of the transplanted blocks in relation to the lesion cavity and the possible mechanical disruption during cutting, unmistakably identifying its location proved difficult. In the transplanted animals, pieces of tissue, sometimes bridged to the host brain, could be detected within the lesion cavity, which presumably may represent the transplanted block of septal tissue.

When qualitatively compared with enzymatic activity in the slices taken from control rats, $\mathrm{AChE}$ histochemistry revealed a marked reduction of the enzyme in the lesioned rats. Figure 5 shows that AChE staining ability was recovered in transplanted animals. One transplanted rat showed no recovery of AChE activity, but nevertheless a normal potentiation was observed. In the remaining transplanted animals, the activity was similar to that seen in the control group. We assume that the apparent recovery of $\mathrm{AChE}$ activity is attributable to a reinnervation from the transplant because such recovery was not seen in any lesioned animal.

\section{DISCUSSION}

The demonstration of an impaired SF potentiation coupled with a normal PS potentiation in the FF-lesioned animals confirms a previous study from our group in which the electrophysiological evaluation was carried out 1 week after lesioning $/ 5 /$. In the present study, an extended delay of 2 months between the lesioning and the onset of the LTP study was introduced with coincident results indicating that, at least within a two-months period, neither spontaneous recovery nor worsening of this function occurs.

Other authors $19,11,17,33 /$ have also reported LTP impairment in FF-lesioned animals, although the particular nature of the dysfunction shows some differences. Buzsaki and Gage /9/ reported an absence of LTP affecting both PS and SF in FFlesioned rats that were tested from 3-5 months after surgery. the authors found that after an initial, short-term potentiation (STP), both parameters decayed to basal levels within 15 minutes after tetanization, which agrees with the SF potentiation in our results. Czéh et al. /11/ studied the consequences of $\mathrm{FF}$ lesion in hippocampal slices taken at several times after the lesioning. The authors reported an abnormal potentiation of the PS in the dentate gyrus of some slices one week after lesioning, whereas the potentiation was affected in all slices taken 4 weeks after the lesioning. They found no alteration in the CAl hippocampal subfield. In another report, Valjakka et al. 133/ described a completely absent PS potentiation 4 minutes after tetanization in rats that had received bilateral FF lesions two months before. The investigators provided no indication concerning the 
SF potentiation Finally, a normal PS potentiation was described in a paper by Kleschevnikov et al. /17/. Despite the differences in particular resultswhich might be due to differences in experimental protocols (different rat strains, using anesthetized or awake animals, different tetanization paradigms), most reports describe some kind of alteration in LTP as a consequence of FF lesion. Such alterations, however, differ from those reported for old animals in which a slower development and a faster decay are the main features of LTP /15/.

In our FF-lesioned rats, we found an impaired SF potentiation in the presence of a normal PS potentiation. Similar results have been described in animals that were tetanized during slow wave sleep 121/. That the PS can be potentiated without a concomitant SF potentiation has been a common finding since the first reports describing LTP /8/. Several factors that are not dependent on an increased synaptic input could contribute to an increased PS. Ephaptic interactions can strongly contribute to the synchronization of discharge; such interactions have been shown to occur in different hippocampal subfields $/ 31,32 /$ that are favored by the high neuronal density in these areas.

An alternative but not excluding possibility is an increased probability that dendritic spikes may be discharged as a result of the activation of dendritic voltage-sensitive channels $/ 34 /$. An increased tendency toward epileptogenic activity has been reported for FF-lesioned rats $19,17 /$. This phenomenon may reflect a pathological deviation of synaptic plasticity to epileptic-like activity rather than a physiologic synaptic enhancement, which plausibly corresponds to the altered potentiation pattern described here and could be causally related to the cognitive impairment seen in FF-lesioned rats.

Our results show that transplanting septal tissue to FF-lesioned rats corrects such alteration, leading to a SF potentiation similar to that observed in sham-operated, control animals. The 'corrected' pattern of potentiation might reflect a normalization of the synaptic plastic changes that are induced by high-frequency stimulation and is likely to be related to the ameliorative effects of similar transplant procedures on the cognitive deficits observed in FFlesioned rats 17,13/. Earlier research on the physiology of transplanted neurons has shown that the discharge of units within a septal transplant and their response to neurotransmitters are similar to those recorded from neurons in the intact septal area $/ 4 /$. A restoration of theta electroencephalographic activity in the hippocampus $/ 30 /$ and a reduction of epileptiform activity /17/ have also been reported after septal transplantation to FFlesioned rats. The results of those studies may indicate that the cells within the transplant are not only alive but also able to sustain normal activity and contribute to a functional normalization of the host tissue.

The FF lesion evokes a complete subcortical denervation, including cholinergic, GABAergic, noradrenergic, and serotonergic fibers. The reinnervation of cholinergic fibers by the transplant seems to be a probable explanation for the recovery of a normal LTP. In the present study, we tried to assess this question by using different subsets of our animal groups for the measurement of ChAT activity and for the histochemical detection of $\mathrm{AChE}$, two enzymes that are involved in cholinergic neuro-transmission. The results of ChAT activity, however, deserve some comment. First, in the lesioned animals, the reduction of enzymatic activity, although significantly lower than that of the controls, was not complete because a relatively high ChAT activity was still measurable. This phenomenon could be related to the use of the whole hippocampus for the determination. That the FF provides cholinergic innervation only to the dorsal region of the hippocampus is well established, whereas the ventral part receives a cholinergic projection through a different route /30/ and is therefore not affected by FF lesion.

Second, a recovery of ChAT activity by the transplant could not be statistically proven, despite the apparent trend in this direction. Perhaps any relative increase in the dorsal aspect of the structure is obscured by the remaining activity in its ventral zone. In one subgroup of transplanted rats, the histological study confirmed a recovery of AChE in the dorsal hippocampus, whereas a complete loss of $\mathrm{AChE}$ was seen in all the lesioned animals. Such results lead us to consider that the dorsal region of the hippocampal formation, where the recordings were made, do suffer a cholinergic denervation as a consequence of the lesion and that the transplantation procedure, as a factor that is likely 
to be involved in the recovery of LTP, allows a partial re-establishment of this innervation in the same region.

The observation in one transplanted rat that despite a normal SF potentiation, the transplant did not induce a visible recovery of AChE activity in the hippocampus raises the possibility that factors other than cholinergic innervation also may be acting in the transplanted animals. The contribution of the GABAergic component on the transplanted tissue for transplant-mediated trophic influences should be considered among the probable ameliorative factors.

Activating the septal input to the dentate gyrus facilitates the activation of the granule cells through entorhinal cortex stimulation $/ 6,29 /$. Although some effect of the GABAergic septal afferents inhibiting the inhibitory hippocampal interneurons cannot be ruled out $16 /$, the effect appears more consistent with a direct action of the septal terminals on granule cells $/ 29 /$. The concurrent tetanization of the perforant path and the septal afferents results in a greater LTP than that produced by tetanization of the entorhinal afferents alone $/ 28 /$. That acetylcholine acting on muscarinic receptors can block $\mathrm{K}^{+}$currents $\left(\mathrm{I}_{\mathrm{M}}, \mathrm{I}_{\mathrm{AHP}}\right)$ is well established $114,25,27 /$. Explaining the absence of LTP in FF-lesioned rats, Buzsaki and Gage /9/ hypothesize that the lack of acetylcholine can provoke a more intense post-potential hyperpolarization that, in turn, prevents the activation of the NMDA receptors that are needed to initiate LTP.

Furthermore, LTP, like memory, has been shown to have phases, the intermediate and later phases being dependent on the activation of protein kinases like protein kinase $\mathrm{C}(\mathrm{PKC})$, on genomic regulation, and on macromolecular synthesis $/ 19,23,26 /$. Cholinergic activation of muscarinic receptors via $G$ proteins can activate phospholipaseC, producing dyacil glycerol and inositol 3phosphate, thereby activating PKC, which by acting on the cell nucleus can modulate gene expression $13 /$. Thus, the deprivation of cholinergic innervation can affect not only the initial induction but also the maintenance of LTP. Indeed, our results and those of Buzsaki and Gage /9/ indicate a defect in LTP maintenance rather than a defect in LTP induction, considering that an initial, short-lasting potentiation does occur. Cholinergic reinnervation via the transplant, even if only partial, can correct this deficit, leading to a normal LTP.

Other evidence $/ 20,22 /$ supports the idea that after FF-lesion, the cognitive deficits, as well as the deficits in LTP, might be caused by the lack of cholinergic innervation. Using 192 IgG-saporin, an immunotoxin that is highly selective for cholinergic neurons, Leanza and coworkers $/ 20 /$ evoked a cognitive deficit that is comparable to that of FF-lesioned rats. Another selective cholinotoxin, $\mathrm{AF} 64 \mathrm{~A}$, has been reported to affect the PS potentiation in the dentate gyrus when a low frequency $(60 \mathrm{~Hz})$ was used to induce LTP but not when a higher frequency $(100 \mathrm{~Hz})$ was used /1/. No indications were presented in that paper about the f-EPSP potentiation, but in CA3 the same toxin blocks the maintenance of an SF potentiation /22/.

In summary, our results confirm that subcortical denervation adversely affects LTP in the rat dentate gyrus. To our knowledge, this work is the first demonstration that transplanting septal fetal tissue can ameliorate the resulting deficits. Current opinion favors the implication of cholinergic innervation, an aspect that we cannot conclusively state. The finding that septal fetal transplants restored LTP in FF-lesioned rats, however, provides new perspectives to explain the cognitive restoration reported for this procedure in animal models and supports the potential use of this surgical approach in treating age-related, cognitive dysfunction.

\section{ACKNOWLEDGMENTS}

The skillful technical assistance of Mr. Juan C. Rosillo is greatly acknowledged.

\section{REFERENCES}

1. Abe K, Nakata A, Mizutani A, Saito H. Facilitatory but nonessential role of the muscarinic cholinergic system in the generation of long-term potentiation of population spikes in the dentate gyrus in vivo. Neuropharmacology 1994; 33: 847-852.

2. Aggleton JP, Keith $A B$, Rawlins JNP, Hunt PR, Sahgal A. Removal of the hippocampus and transection of the fornix produce comparable deficits on delayed non-matching to position by rats. Behav Brain Res 1992; 52: 61-71. 
3. Armstrong RC, Montminy MR. Transsynaptic control of gene expression. Ann Rev Neurosci 1993; 16: 1729.

4. Bassant $\mathrm{MH}$, Joly $\mathrm{M}$, Nilsson $\mathrm{OG}$, Björklund $\mathrm{A}$, Lamour Y. Electrophysiological and pharmacological properties of neurons within solid basal forebrain transplants in the rat brain. Brain Res 1988; 460: 816.

5. Bergado JA, Moreno $H$, Nuñez B, Fimbria-fornix lesion impairs long-term potentiation in the dentate gyrus of the rat. Biol Res 1996; 29: 197-202.

6. Bilkey DK, Goddard GV. Medial septal facilitation of hippocampal granule cell activity is mediated by inhibition of inhibitory interneurons. Brain Res 1985; 361: 99-106.

7. Björklund A, Gage FH. Neural grafting in animal models of neurodegenerative disease. Ann NY Acad Sci 1985 ; 444: 53-81.

8. Bliss TVP, Lomo T. Long-lasting potentiation of synaptic transmission in the dentate area of the anaesthetized rabbit following stimulation of the perforant path. J Physiol (London) 1973; 232: 331356.

9. Buzsáki G, Gage FH. Absence of long-term potentiation in the subcortically deafferented dentate gyrus. Brain Res 1989; 484: 94-101.

10. Cassel JC, Ballough GP, Kelche C, Hofferer E, Cassel $\mathrm{S}$, Will B. Injections of fluid or septal cell suspension grafts into the dentate gyrus of rats induce granule cell degeneration. Neurosci Lett 1993; 150: 89-94.

11. Czéh G, Horvath Z, Czopf J. Time course of changes in long-term potentiation of synaptic transmission following subcortical deafferentation on the rat hippocampus. Acta Physiol Hung 1992; 79: 77-93.

12. Fonnum FJ. A rapid method for the determination of choline acetyltransferase. J Neurochem 1975; 24 : 407 409.

13. Francis Turner $\mathrm{L}$, Nuñez Rodriguez $\mathrm{N}$, Castellano Benitez O, Moreno Granados H, Fernández Verdecia I, de la Cuétara Bernal K, Macías Gonzales R. Spatial learning and memory following fimbria-fornix lesion and intrahippocampal grafts. In: Beregi E, Gergely IA, Rajczi K, eds, Recent Advances in Aging Science. Bologna: Monduzz Ed. 1993; pp. 1245-1248.

14. Gähwiler BH. Facilitation by acetylcholine of tetrodotoxin-resistant spikes in rat hippocampal pyramidal cells. Neuroscience 1984; 11: 381-388.

15. Geinisman Y, DeToledo-Morrel L, Morrel F, Heller RE. Hippocampal markers of age-related memory dysfunction: Behavioral, electrophysiological and morphological perspectives. Prog Neurobiol 1995; 45: 223-252.

16. Karnovsky MJ, Roots L. A “direct coloring" thiocholine method for cholinesterases. J Histochem Cytochem 1963; 12: 219.

17. Kleschevnikov AM, Sinden JD, Marchbanks R. Fimbria-fornix lesions impair spatial performance and induce epileptic-like activity but do not affect longterm potentiation in the CA1 region of rat hippocampal slices. Brain Res 1994; 656: 221-228.

18. Krug M, Bergado J, Rüthrich $\mathrm{H}$. Long-term potentiation and postconditioning potentiation-the same mechanism? Biomed Biochim Acta 1990; 49: 273279.

19. Krug M, Lössner B, Ott T. Anisomycin blocks the late phase of long-term potentiation in the dentate gyrus of freely moving rats. Brain Res Bull 1984; 13: 39-42.

20. Leanza G, Nilsson OG, Wiley RG, Björklund A. Selective lesioning of the basal forebrain cholinergic system by intraventricular 192 IgG-saporin: Behavioural, biochemical and stereological studies in the rat. Eur J Neurosci 1995; 7: 329-343.

21. Leonard BJ, McNaughton BL, Barnes CA. Suppression of hippocampal synaptic plasticity during slow wave sleep. Brain Res 1979; 233-245.

22. Maeda T, Kaneko S, Satoh M. Roles of endogenous cholinergic neurons in the induction of long-term potentiation at hippocampal mossy fiber synapses. Neurosci Res 1994; 20: 71-78.

23. Matthies $H$. Neurobiological aspects of learning and memory. Ann Rev Psychol 1989; 40: 381-404.

24. Matthies H, Rüthrich H, Ott T, Matthies HK, Matthies $R$. Low frequency perforant path stimulation demonstrates correlations between long-term synaptic potentiation and learning. Physiol Behav 1986; 36: 811-821.

25. Nicoll RA. The septo-hippocampal projection: A model cholinergic pathway. Trends Neurosci 1985; 8: 533-536.

26. Nikolaev E, Tischmeyer W, Krug M, Matthies H, Kaczmarek L. c-fos protooncogene expression in rat hippocampus and entorhinal cortex following tetanic stimulation of the perforant path. Brain Res 1991; 560: 366-349.

27. Pontzer NJ, Madamba S, Siggins GR, Crews FT. Concentrations of carbachol stimulating phospho-inositide hydrolysis cause a sustained decrease in membrane potential and firing rate: Role of inositol and inositol polyphosphate second messengers. Brain Res 1992; 597: 189-199.

28. Robinson GB, Racine RJ. Heterosynaptic interactions between septal and entorhinal inputs to the dentate gyrus: Long-term potentiation effects. Brain Res 1982; 249: 162-166.

29. Robinson GB, Racine RJ. Interactions between septal and entorhinal inputs to the dentate gyrus: Facilitation effects. Brain Res 1986; 379: 63-67.

30. Segal M, Richter-Levin G. Electrophysiologic analysis of grafts in the hippocampus. In: Dunnet SB, Björklund A, eds, Functional Neural Transplantation. New York: Raven Press, 1994; pp. 317-325.

31. Taylor CP, Dudek FE. Excitation of hippocampal pyramidal cells by an electric field. J Neurophysiol $1984 ; 52$ : 126-142. 
32. Turner RW, Richardson TL, Miller JJ. Ephaptic interactions contribute to paired pulse and frequency potentiation of hippocampal field potentials. Exp Brain Res 1984; 54: 567-570.

33. Valjakka A, Lukkarinen $\mathrm{K}$, Koivisto E, Lammintausta R, Airaksinen MM, Riekkinen P. Evoked field responses, recurrent inhibition, long-term potentiation and immobility-related nonrhythmical EEG in the dentate gyrus of fimbria-fornix-lesioned and control rats. Brain Res Bull 1991; 26: 525-532.

34. Vida I, Czopf J, Czéh G. A current-source density analysis of the long-term potentiation in the hippocampus. Brain Res 1995; 671: 1-11. 

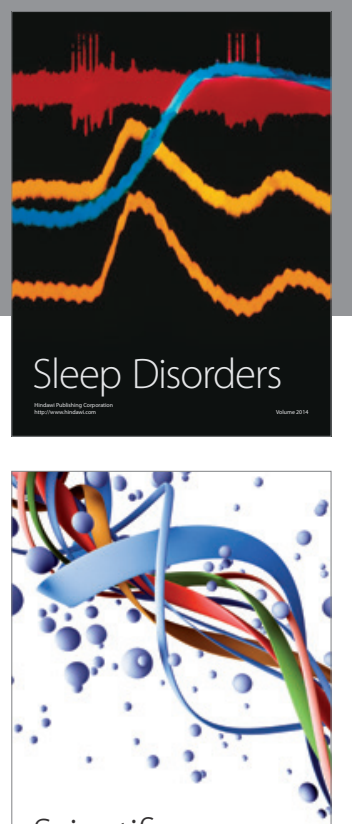

Scientifica
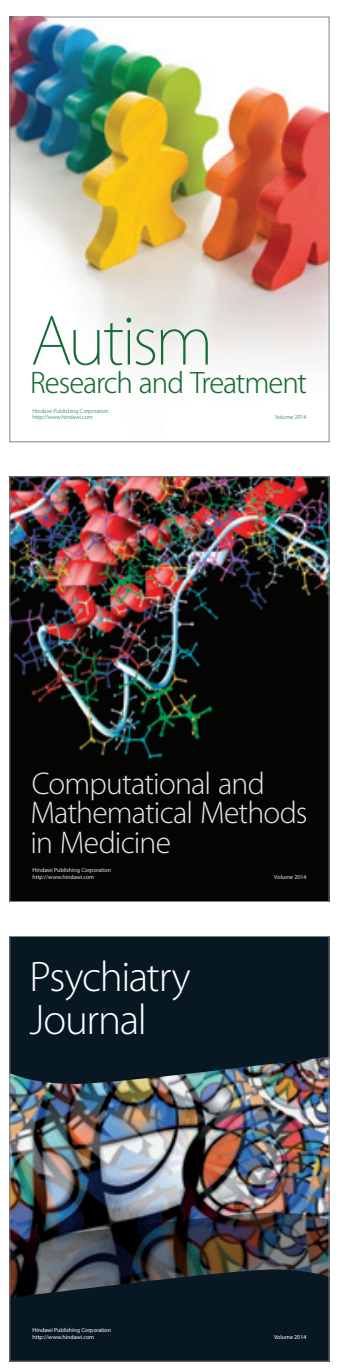
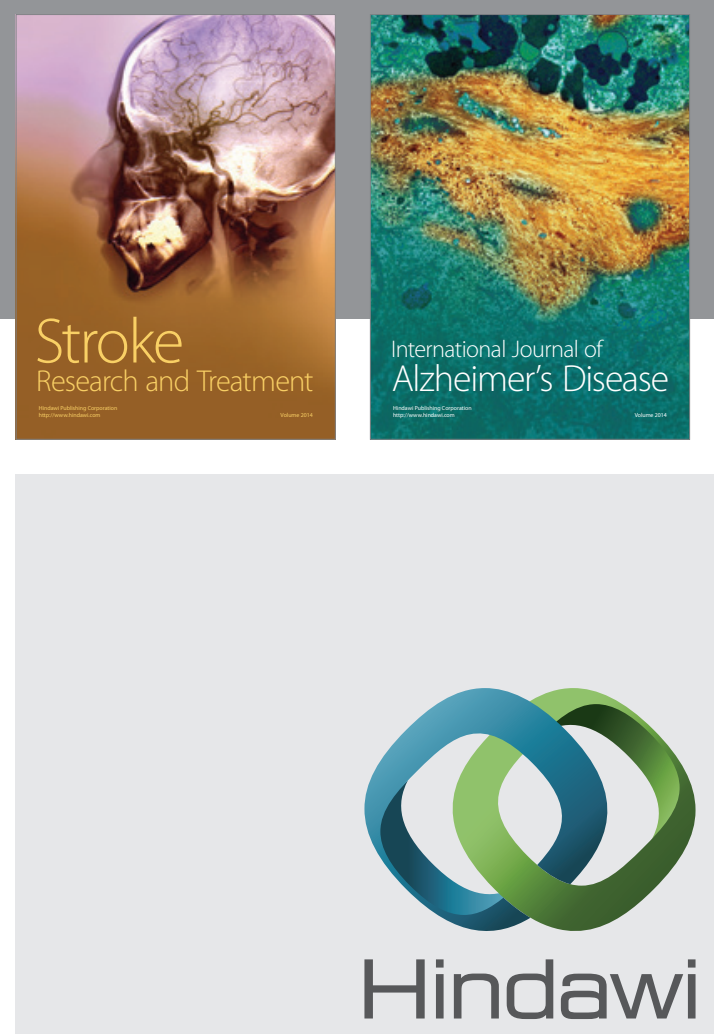

Submit your manuscripts at

http://www.hindawi.com
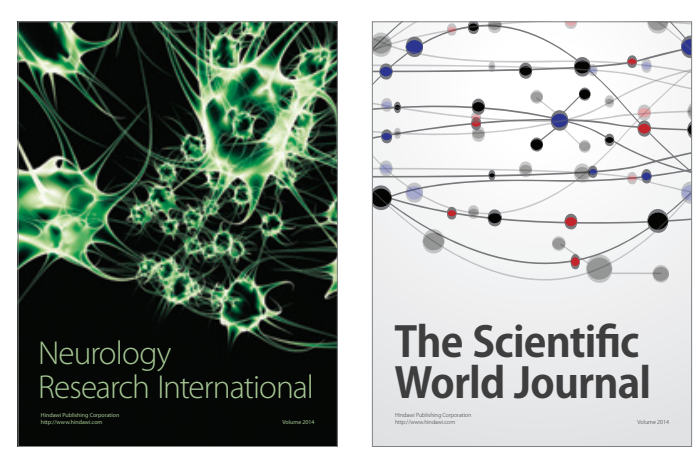

The Scientific World Journal

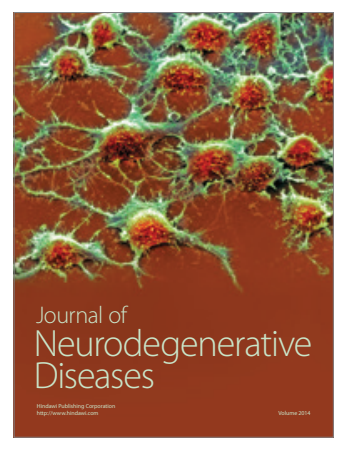

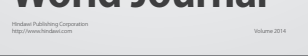

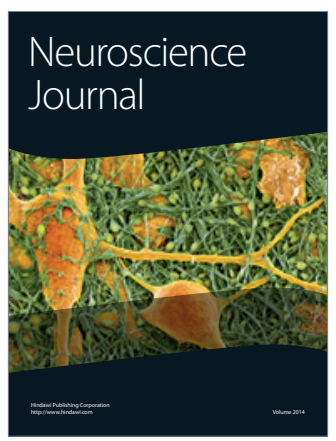

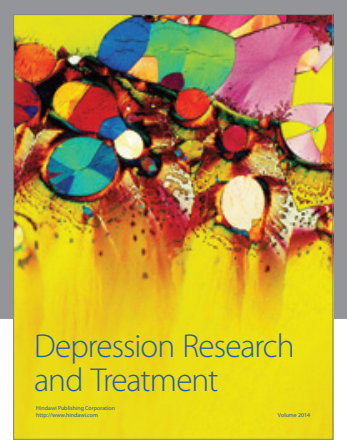
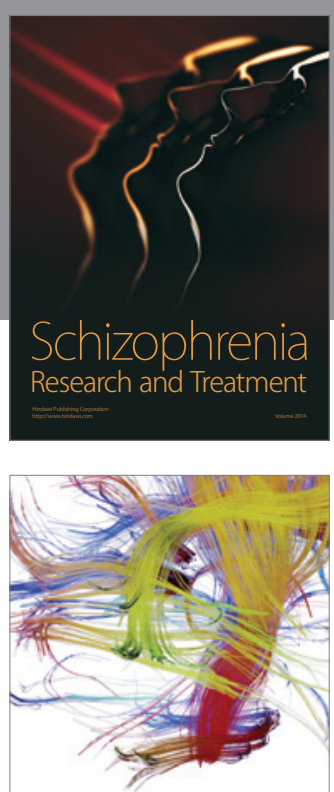

Brain Science

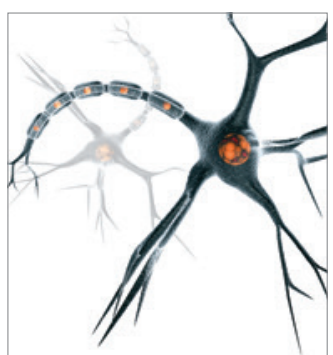

Neural Plasticity
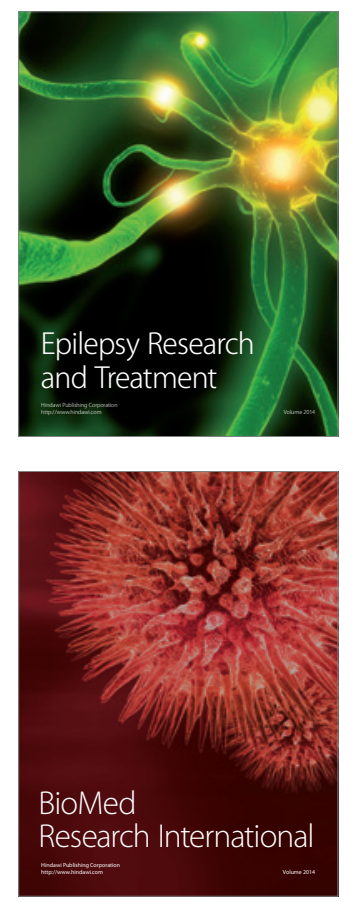

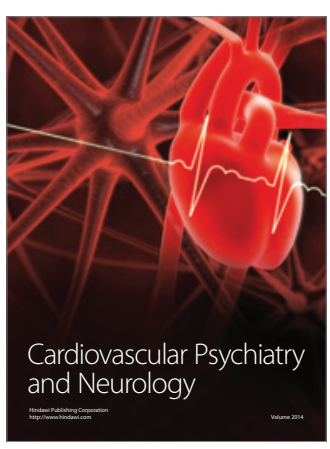

Parkinson's

Disease
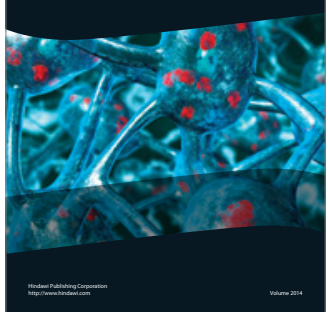